\title{
Jean-Claude Gorjy, 'Ann' Quin Bredouille ou le Petit Cousin de Tristram Shandy (1791-1792)
}

\section{Regina Bochenek-Franczakowa}

\section{(2) OpenEdition}

1 Journals

\section{Édition électronique}

URL : https://journals.openedition.org/studifrancesi/3094

DOI : 10.4000/studifrancesi.3094

ISSN : 2421-5856

\section{Éditeur}

Rosenberg \& Sellier

\section{Édition imprimée}

Date de publication : 1 juillet 2013

Pagination : 455

ISSN : 0039-2944

\section{Référence électronique}

Regina Bochenek-Franczakowa, « Jean-Claude Gorjy, 'Ann' Quin Bredouille ou le Petit Cousin de Tristram Shandy (1797-1792) », Studi Francesi [En ligne], 170 (LVII | II) | 2013, mis en ligne le 30 novembre 2015, consulté le 02 février 2023. URL : http://journals.openedition.org/studifrancesi/3094 ; DOI : https:// doi.org/10.4000/studifrancesi.3094

Ce document a été généré automatiquement le 2 février 2023.

\section{(c) $(1)$}

Creative Commons - Attribution - Pas d'Utilisation Commerciale - Pas de Modification 4.0 International - CC BY-NC-ND 4.0

https://creativecommons.org/licenses/by-nc-nd/4.0/ 


\title{
Jean-Claude Gorjy, 'Ann' Quin Bredouille ou le Petit Cousin de Tristram Shandy (1791-1792)
}

\author{
Regina Bochenek-Franczakowa
}

\section{RÉFÉRENCE}

JEAN-CLAUDE GORJY, 'Ann' Quin Bredouille ou le Petit Cousin de Tristram Shandy (1791-1792), Huguette KRIEF (éd.), Paris, Honoré Champion, 2012, pp. 597.

1 Les spécialistes ainsi que les lecteurs amateurs du roman français de l'époque révolutionnaire salueront avec une grande joie la réédition du roman de Jean-Claude Gorjy, dans l'excellente édition critique de Huguette Krief, éminente spécialiste de la littérature de la même période. Ce roman, un des meilleurs de cette décennie, n'était jusqu'à présent accessible que dans les vieux fonds de quelques bibliothèques et, partiellement, sur Gallica (la moitié de l'ensemble). On a sorti de l'oubli cette œuvre et son auteur dans les années 1980, en plaçant Jean-Claude Gorjy dans la lignée des romanciers sentimentaux de la fin du siècle; son dernier roman, énigmatique et «insolite», suscite pourtant un intérêt marqué d'étonnement. Dans son Introduction, $\mathrm{H}$. Krief brosse la silhouette de l'auteur à la «biographie incertaine», silhouette qui se laisse saisir avant tout à travers ses écrits et textes. Grand admirateur de Laurence Sterne, Gorjy s'avère être aussi un homme fort cultivé, dont l'érudition, typique du $\mathrm{XVIII}^{\mathrm{e}}$ siècle, vise des lecteurs avisés qui ont à le comprendre à demi-mot. H. Krief souligne l'originalité de cette œuvre décousue qui représente «un monde romanesque déréglé», tant au niveau de la forme que du contenu, ce dont témoignent, d'un côté, la fragmentation et l'inachèvement, les suppressions et omissions, la déconstruction des épisodes, de l'autre, une recherche d'équilibre, d'avance vouée à l'échec, dans un monde de la violence et de l'absurde. H. Krief considère le roman de Gorjy avant tout dans le contexte de la littérature satirique des Lumières et celle, pamphlétaire, de la 
Révolution. Elle souligne aussi, à juste titre, le caractère étonnamment moderne de la forme «ouverte» de ce roman. Les notes, très compétentes et riches dont l'éditrice éclaire le texte sont fort précieuses pour le lecteur. H. Krief y explique les nombreux néologismes inventés par Gorjy, les expressions vieillies, les jeux de mots et charades. L'éditrice déchiffre les allusions dont le texte est émaillé, aux personnes et faits de la Révolution, aux écrits du jour. Elle retrouve les sources des citations littéraires (parfois, doit les rectifier), indique les rapports intertextuels, enfin, explique les références à l'histoire et la littérature, de l'Antiquité au XvIII ${ }^{e}$ siècle. Au lecteur de découvrir ensuite ce roman dont il est impossible de fixer le caractère dominant. Sentimental, pamphlétaire, satirique, ironique? Il est tout cela à la fois, se développant entre un incipit qui n'en est pas un et une clôture en suspens, se déroulant à un rythme irrégulier, fou, saccadé et nerveux dont la dynamique, observe $\mathrm{H}$. Krief, rappelle celle de la Révolution elle-même.

Soulignons encore que cette édition moderne est fort soignée; elle reproduit le côté typographique, la division en chapitres, les planches, dessins et notes de musique. $\mathrm{H}$. Krief nous a donné à lire les six volumes («fagots» selon Gorjy) tels qu'ils se présentent dans l'édition originale, avec une exception: manque la nouvelle intitulée L'Aristocrate converti ou le retour de Coblentz qui fermait le sixième volume. H. Krief ne croit sans doute pas que cette nouvelle soit de la plume de Gorjy: reste que le lecteur aurait dû en être informé. C'est l'unique objection à faire à cette édition. Il faut insister: on n'a qu'à féliciter, et l'éditrice et la maison d'édition d'avoir enfin donné accès au chef-d'œuvre de Gorjy au plus large public. 